\title{
Infection dynamics of Kudoa yasunagai (Myxozoa: Multivalvulida) infecting brain of cultured yellowtail Seriola quinqueradiata in Japan
}

\author{
Sho Shirakashi", Akinobu Morita, Katsuya Ishimaru, Shigeru Miyashita
}

Fisheries Laboratory, Kinki University, Shirahama, Wakayama 649-2211, Japan

\begin{abstract}
We monitored infection by a brain-infecting myxozoan Kudoa yasunagai in hatchery-reared juvenile yellowtail Seriola quinqueradiata at a culturing site in Japan. Infection was detected by PCR and microscopic observation once every 1 to 4 wk during 2010 and 2011. In both years, we detected first infection in mid-July by PCR. Prevalence increased rapidly after the onset of infection, peaking at $100 \%$ within 4 wk. Parasites required less than $10 \mathrm{~d}$ to reach the brain after invasion. Development of plasmodia and formation of cysts took 4 to $8 \mathrm{wk}$. Infection did not reach a plateau and number of cysts tended to decline over time, suggesting possible recovery from the infection. A drastic decline in infection prevalence was observed during the season of highest water temperature $\left(>30^{\circ} \mathrm{C}\right)$ in 2010 . To understand this phenomenon, we conducted a laboratory experiment to compare infection prevalence and cyst formation in fish kept at $25^{\circ} \mathrm{C}$ and $30^{\circ} \mathrm{C}$. However, we could not detect obvious differences between the treatment groups during the $4 \mathrm{wk}$ of the experiment. There was no apparent pathology associated with the infection. These results suggest that pathological effects of $K$. yasunagai may differ between fish species or that other factors are important in the development of infectious signs.
\end{abstract}

KEY WORDS: Myxozoan $\cdot$ Seasonality $\cdot$ Cyst development $\cdot$ Water temperature - Resale or republication not permitted without written consent of the publisher

\section{INTRODUCTION}

Kudoa yasunagai (Hsieh et Chen, 1984), originally described as Septemcapsula yasunagai, is a multivalvulid myxozoan infecting brains of various marine fish. Since the original finding from Japanese seabass Lateolabrax japonicus and striped knifejaw Oplegnathus fasciatus (Yasunaga et al. 1981), the parasite has been reported from several important aquaculture fishes in Japan, including red sea bream Pagrus major, olive flounder Paralichthys olivaceus, tiger puffer Takifugu rubripes, yellowtail Seriola quinqueradiata and Pacific bluefin tuna Thunnus orientalis (Egusa 1986a,b, Whipps et al. 2004, Zhang et al. 2010). It has also been reported from several wild fish in other parts of the world, such as coral catfish Plotosus lineatus in the Philippines (Cheung \& Nigrelli 1990), whitings Sillago spp., and monocle bream Scolopsis monogramma from Australia
(Burger \& Adlard 2010). Such low host specificity and wide geographical distribution make this parasite a potential threat to marine aquaculture and wild fish resources.

Typical clinical signs of Kudoa yasunagai infection in the fish host are abnormal behavior and skeletal deformation. Spinal curvature and/or abnormal swimming in several commercially important fish, including Japanese sea bass, yellowtail, and chub mackerel Scomber japonicus, are thought to be due to K. yasunagai infection (Yasunaga et al. 1981, Egusa 1986a, Yamamoto 2007). In 2011, we experienced large mortalities of juvenile kingfish Seriola lalandi in our culturing facilities in Wakayama, Japan. The hatchery-reared fish started to show signs of infection at about 2 mo after being transferred to net cages. A considerable proportion (exact number not counted, but over $50 \%$ ) of fish developed S-shaped spinal curvature (scoliosis) and abnormal 
swimming such as whirling or lying on the bottom of the cages. The symptomatic fish had difficulty feeding and suffered from damaged skin due to swimming into the cage net, causing them to die eventually. The infection prevalence of $K$. yasunagai among those fish was over $80 \%$, and we suspected this parasite to be the cause of the problem.

To date, there is no effective control method for Kudoa yasunagai, or any other Kudoa sp., in aquaculture. One possible way to reduce the parasite damage in a fish farm is to manage the production schedule so fish are not in the open-water cages during the season when infectious parasites are most abundant. However, information about the seasonality of $K$. yasunagai is very scarce, and its infection dynamics are not understood. We conducted a long-term monitoring study and a laboratory experiment aiming to determine (1) the onset and progression of $K$. yasunagai infection in a fish farm and (2) the effect of temperature on parasite development. The purpose of the present study is to obtain basic information about infection dynamics of $K$. yasunagai in order to develop a management strategy to minimize its impact on net cage aquaculture.

\section{MATERIALS AND METHODS}

\section{Infection monitoring}

We investigated the temporal change of Kudoa yasunagai infection at the culturing site in 2010 and 2011 using $K$. yasunagai-free juvenile yellowtail Seriola quinqueradiata that were raised from eggs in a land-based hatchery. For the experiment, approximately 700 and 400 juvenile fish in 2010 and 2011, respectively (body weight 27.2 $\pm 5.2 \mathrm{~g}$ for 2010, $2.5 \pm$ $0.4 \mathrm{~g}$ for 2011) were transferred to a net cage $(3 \times 3 \times$ $3 \mathrm{~m}$ ) in the ocean and were monitored for parasite infection by both microscopy and PCR. We checked 20 individuals prior to the experiment using PCR described below and confirmed that there was no Kudoa infection. For 2010 juveniles, infection was monitored for 15 mo between May 16, 2010 and August 15, 2011. Ten fish were sampled every week for the first $5 \mathrm{mo}$, every second week for the following 5 mo and then at 1 mo intervals for the last 5 mo. For 2011 juveniles, we monitored infection for 1 mo from July 2, to August 3, 2011 by checking 10 individuals every week.

At each sampling, we collected fish from the net cage using a dip net and kept them on ice until dissection. We measured the body size of individual fish, and their brains were removed. The surface of brain and cranial cavity was checked thoroughly under a dissecting scope for the presence of parasite cysts (plasmodium). The total number of cysts was recorded and the parasite was identified by examining spore morphology in a squashed preparation of randomly selected cysts. In cases where no cysts were visible, PCR diagnosis was performed. DNA was extracted from a portion (approx. $20 \mathrm{mg}$ ) of the brain homogenate using the phenol-chloroform method. PCR was performed with primer sets designed to target 18S rDNA of Kudoa spp. (610 bp); yassuf (5'-AAC CTA GTG TTT CGG CTT CG-3') and yassur (5'-CTT TTC CCC ACA ACG TCA AG-3'). The PCR reaction mixture contained $0.3 \mu \mathrm{M}$ of each primer, $10 \mu \mathrm{l}$ of Takara EmeraldAmp PCR MasterMIX $(2 \times)$, and $1 \mu \mathrm{l}$ template DNA, and was topped up to $20 \mu \mathrm{l}$ with $\mathrm{H}_{2} \mathrm{O}$. Cycling protocol comprised an initial denaturation at $95^{\circ} \mathrm{C}$ for $3 \mathrm{~min}$, followed by 35 cycles of $94^{\circ} \mathrm{C}$ for $30 \mathrm{~s}, 58^{\circ} \mathrm{C}$ for $30 \mathrm{~s}$ and $72^{\circ} \mathrm{C}$ for $30 \mathrm{~s}$ followed by a final extension of $72^{\circ} \mathrm{C}$ for 10 min. PCR products were separated on a $2 \%$ agarose gel. To assure the identity of the amplified product with the sequence of $K$. yasunagai, PCR products were sequenced (Meng et al. 2011) from 3 randomly selected isolates obtained in different seasons. Obtained sequences were compared with the data in GenBank.

Throughout the experiment, fish were fed with commercial dry pellets every other day to satiation and checked for mortality. Fresh water-bath treatments were performed on several occasions to control skin fluke Benedenia seriolae and Neobenedenia girellae infections. Surface water temperature was recorded daily. Any abnormalities in sampled fish, such as spinal curvature or malformation, were recorded with photographs.

\section{Temperature experiment}

During the monitoring experiment, we noticed an unexpected sharp decline of infection prevalence during the period of highest water temperature (ca. $30^{\circ} \mathrm{C}$ ). To understand this phenomenon we conducted a laboratory experiment to test whether high water temperature could reduce Kudoa yasunagai infection. The laboratory experiment was conducted in August 2011 when the infection prevalence of 2011 juveniles reached 95\%. All infections in those fish were detected by the PCR and no cysts were observed at the time. One hundred and forty fish were removed from the net cage and divided into 
two $500 \mathrm{l}$ tanks, which were set at $30^{\circ} \mathrm{C}$ (average $\left.30.4 \pm 0.73^{\circ} \mathrm{C}\right)$ or $25^{\circ} \mathrm{C}\left(24.8 \pm 0.67^{\circ} \mathrm{C}\right)$ with electric heating and cooling systems. The surface water temperature at the culturing site at the time of transfer was $28.6^{\circ} \mathrm{C}$. Fish were kept at the 2 temperature conditions for 4 wk. Twenty fish were sampled from each group at 1,2 and 4 wk for checking $K$. yasunagai infection using the methods described above. The experimental tanks were provided with flow through water (4.8 1 $\min ^{-1}$ ) and the temperature was recorded hourly. Fish were fed every other day with dry pellets ad libitum. Fresh water-bath treatments were performed at the beginning and $2 \mathrm{wk}$ after the experiment was started.

\section{Statistical analyses}

At each sampling, encysting prevalence and infection prevalence were calculated. Encysting prevalence was determined as the proportion of fish with apparent cysts on the brain surface. Infection prevalence was determined as the proportion of individuals with cysts plus those identified positive by the PCR. Average number of cysts was calculated from the fish possessing cysts (excluding the fish without cysts). Difference in prevalence between each sampling time point was tested using a Pearson chi-square test. Spearman's correlation test was used to understand the temporal change in the number of cysts. Numbers of cysts between the 2 experimental groups were compared using a Wilcoxon rank-sum test. All analyses were performed using JMP8 (SAS Institute).

\section{RESULTS}

\section{Infection monitoring}

The spores we observed during the study possessed 6 to 7 polar capsules, and their morphology resembled the description of Kudoa yasunagai (Hsieh \& Chen 1984, Burger \& Adlard 2010). The DNA sequences of randomly sampled cysts were all identical with a $K$. yasunagai isolate in Genbank (Accession No. AY302741).

In 2010, we detected the first Kudoa yasunagai infection by PCR on July 19, which was 9 wk after the fish had been transferred into the net cage. The

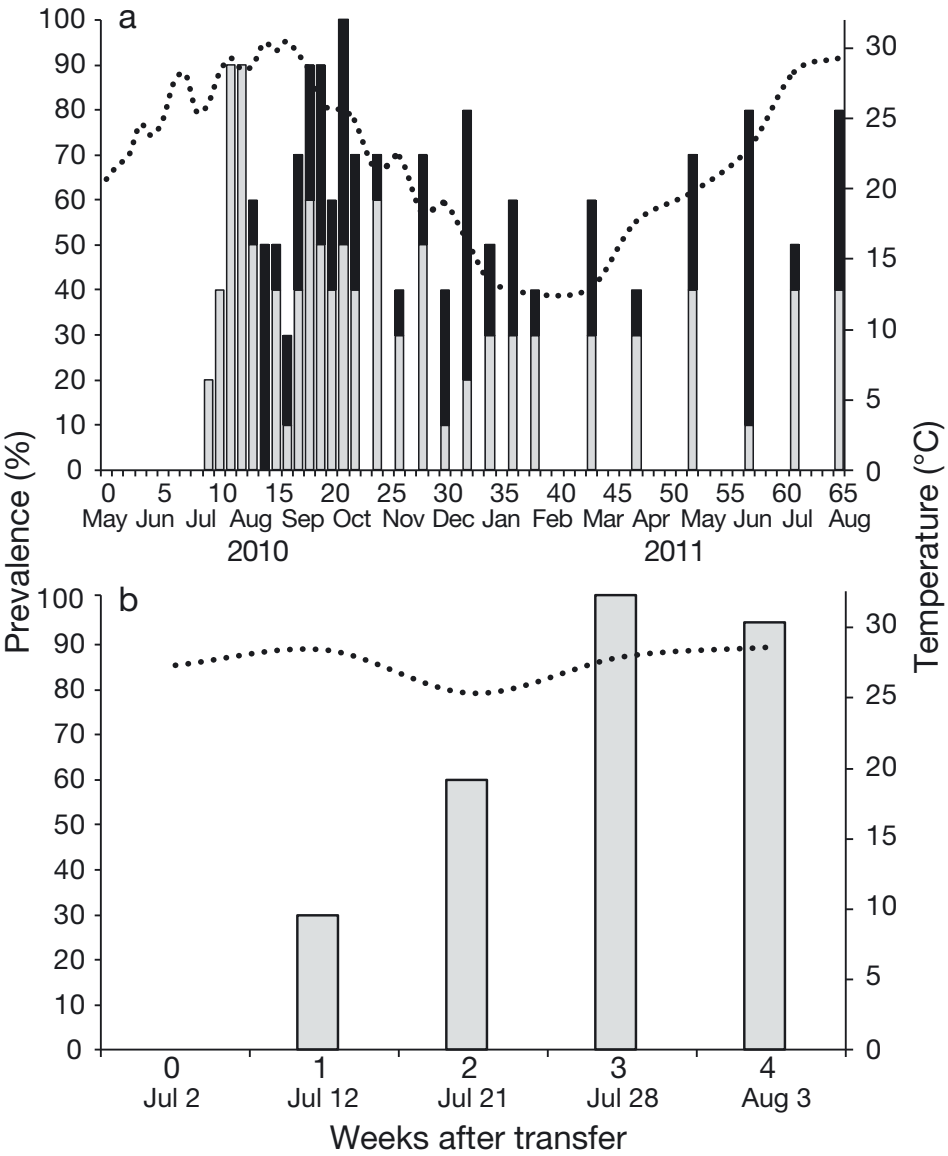

Fig. 1. Kudoa yasunagai infecting Seriola quinqueradiata. Seasonal change of infection prevalence in juvenile yellowtail after transfer from hatchery to net cages in open water as detected by PCR (grey bar) and visual determination (black bar) of the presence of cysts on the brain surface, during (a) 2010, when the date of transfer was May 16, and (b) 2011, when the date of transfer was July 2. Dotted line: surface water temperature

infection prevalence drastically increased thereafter from 20 to $90 \%$ in the following $3 \mathrm{wk}$ (Fig. 1). After reaching the first peak in early August, the prevalence declined to as low as $30 \%$ in the beginning of September. This sudden decline of the infection appeared to correspond to the high water temperature, which reached a peak of over $30^{\circ} \mathrm{C}$ at the time (Fig. 1). After the decline, the infection reached a second peak of $100 \%$ prevalence in mid-October and stayed within the range of 40 to $80 \%$ thereafter. In 2011 juveniles, the onset of infection occurred at around the same time as in 2010, even though the 2011 fish were transferred to the net cages 1.5 mo later compared to 2010. Also, the progression of infection in 2011 was similar to 2010. We first detected infection on July 12, 2011, a week after the fish had been placed in the net cage (Fig. 1). Infection then increased rapidly, reaching $100 \%$ within 3 wk. 


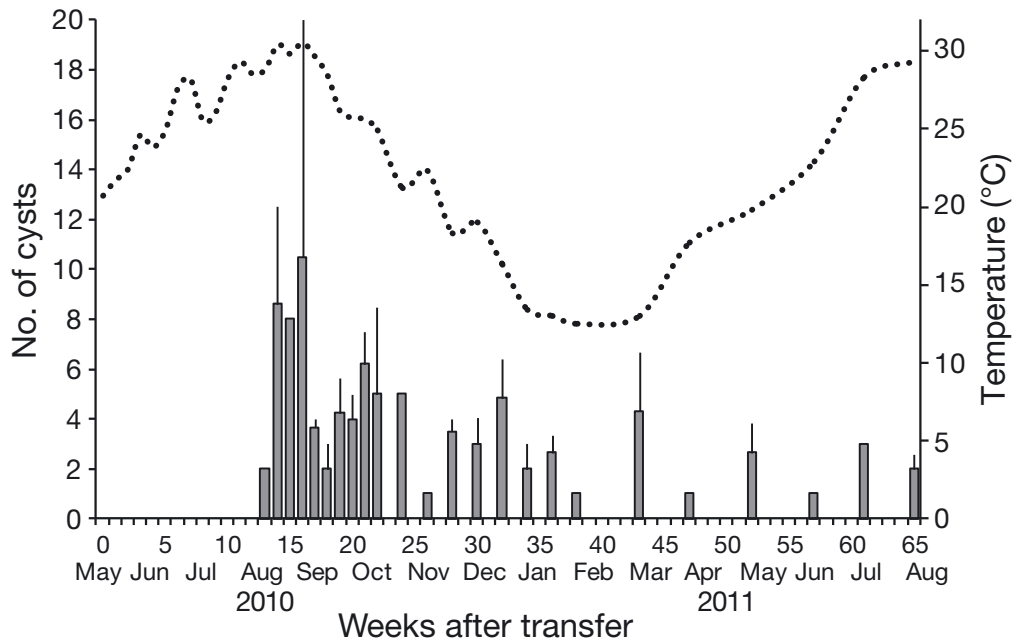

Fig. 2. Kudoa yasunagai infecting Seriola quinqueradiata. Seasonal changes in the average $(+\mathrm{SE})$ number of cysts. Dotted line: surface water temperature

These fish were subsequently used for the laboratory experiment.

We observed the first cysts in 2010 fish on August 16, 4 wk after our initial detection by the PCR diagnosis (Fig. 1). The encysting prevalence was variable between the samples and did not show an obvious increase as we expected. It remained between 10 and $60 \%$ throughout the experiment except for one sampling in August where cysts were detected in all infected fish (Fig. 1). Fig. 2 shows the change in the average number of cysts during the monitoring period. After the first detection, cyst number rapidly increased for several weeks, and then gradually declined during the rest of the experimental period. Overall, there was a significant negative correlation between the number of cysts and the monitoring weeks (Fig. 2; Spearman's rho $=-0.44, \mathrm{p}=0.0002$ ). No cysts were observed during our 5 wk monitoring of 2011 fish.

During the 2 yr monitoring, a total of only 6 mortalities were noted. All deaths were of 2010 juveniles and occurred mostly during the summer when skin fluke infections were severe. We noticed occasional abnormal swimming behaviors such as flashing and sudden erratic movement, but they were most likely associated with skin fluke infections. We did not see any individuals showing whirling or lying on the cage bottom as seen for the infected kingfish. Out of nearly 500 sampled fish, 6 showed apparent spinal deformities. Their heads were bent upward showing a V-shaped spinal curvature (lordosis) and not an Sshaped curvature (scoliosis) which was commonly observed for the infected kingfish. Infection preva- lence of Kudoa yasunagai among these deformed fish was $33 \%$ ( 2 out of 6 fish). We did not notice any obvious inflammation or pathological signs on the brain surface.

\section{Temperature experiment}

Temporal change of the infection prevalence for the 2 temperature treatments is shown in Fig. 3. The prevalence increased and reached $100 \%$ by 4 and 2 wk in the $25^{\circ} \mathrm{C}$ and $30^{\circ} \mathrm{C}$ treatments, respectively. For $30^{\circ} \mathrm{C}$ groups, infection prevalence then appeared to decline at the end of the experiment. However, the difference in prevalence was not significant between sampling weeks within either group. Infection prevalence between the treatments did not differ at $1 \mathrm{wk}$, but the difference became significant at 2 and $4 \mathrm{wk}\left(\chi^{2}{ }_{1}=21.20, \mathrm{p}<0.0001, \chi^{2}{ }_{1}=22.01\right.$, $\mathrm{p}<0.0001$, respectively). The encysting prevalence increased over time and reached over $60 \%$ in both groups at the end of the experiment (Fig. 3). There was no statistical difference in the encysting prevalence between the temperatures at any week.

We did not detect cysts at the beginning of the experiment, but as many as 20 cysts were found in some fish only after a week (Fig. 4). Cysts numbers then increased rapidly, reaching an average of about 40 (maximum 120 cysts on a brain) at 4 wk. There was no statistical difference in cyst numbers between the groups at any sampling point. No fish died during the experiment, and we did not notice any obvious abnormality or deformity.

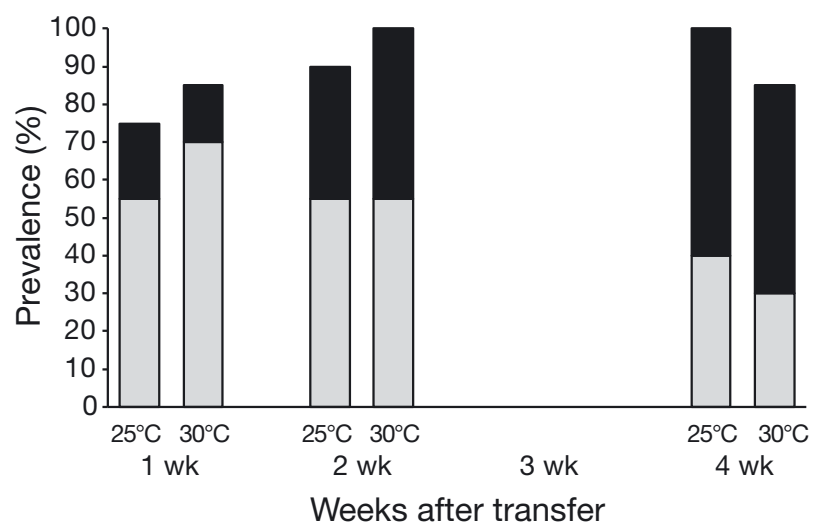

Fig 3. Kudoa yasunagai infecting Seriola quinqueradiata. Infection prevalence detected by PCR (grey bars) and visual detection (black bars) of the presence of cysts for fish kept at $25^{\circ} \mathrm{C}$ and $30^{\circ} \mathrm{C}$ over the first $4 \mathrm{wk}$ after transfer 


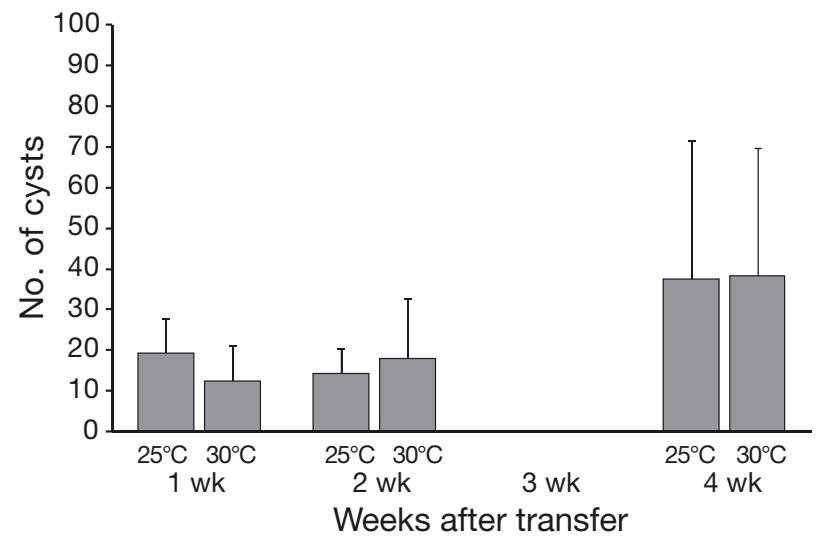

Fig. 4. Kudoa yasunagai infecting Seriola quinqueradiata. Average $(+\mathrm{SE})$ number of cysts found in fish kept at $25^{\circ} \mathrm{C}$ and $30^{\circ} \mathrm{C}$ over the first $4 \mathrm{wk}$ after transfer

\section{DISCUSSION}

Infection of Kudoa yasunagai in the monitored farming site started around mid July. Since we did not detect any signs of infection during land-based rearing, we can assume that the fish acquired the parasite after they had been transferred to the net cages. The first infection was detected at a similar time in both 2010 (July 12) and 2011 (July 19) despite the time difference in transferring fish to the net cages (May or July). This is consistent with a previous report that $K$. yasunagai infection in cultured tiger puffer in Nagasaki prefecture, Japan, starts in mid-July (H. Yokoyama pers. comm.). In the present study, we observed drastic increases of initial infection prevalence in both 2010 and 2011, 0 to $90 \%$ and 0 to $100 \%$ within $3 \mathrm{wk}$, respectively. Certain environmental and biological cues that are characteristics of this time of the year likely trigger the release of $K$. yasunagai actinospores from an unidentified invertebrate, resulting in a high abundance of the infective parasite stages in the water column. Such sharp increase of prevalence is commonly observed in myxozoans showing seasonal infection. Moran et al. (1999b) reported that infection prevalence of K. thyrsites in Atlantic salmon Salmo salar increased from 0 to $80 \%$ within $3 \mathrm{wk}$ at the end of June. Similarly, infection of Tetracapsuloides bryosalmonae, Chloromyxum schurovi, and Myxobolus sp. in brown trout $S$. trutta fry increased from 0 to $>80 \%$ within a 1 mo period (Holzer et al. 2006). Many myxozoan infections occur in the spring and early summer when naïve young fish hosts are abundant (Markiw 1991, 1992, Kent et al. 1994, Moran et al. 1999c, Holzer \& Schachner 2001). Actinospores of M. cerebralis are released at temperatures of 15 to $16^{\circ} \mathrm{C}$, when suscep- tible rainbow trout fry are abundant (Markiw 1991, 1992, Kent et al. 2001). K. yasunagai has low host specificity and possibly utilizes multiple fish species as a host. Spring through early summer is the breeding seasons for many marine fishes, and the parasite's strategy may be to release the infective stage during this period when high densities of juvenile hosts are available.

We suspected that a high density of infective parasite in mid-July caused the sudden increase of infection level. However, we checked infection only in the brain, and how long before infection the fish acquired the parasite is not clear. Myxozoans invade a fish body via skin, fins, buccal cavity and/or gills (Yokoyama et al. 2012). The infection route of Kudoa yasunagai is still unknown, but migration to the brain may require some time. Dzulinksy et al. (1994) reported that developing plasmodia of Myxobolus neurophilus, a brain-infecting myxozoan of yellow perch Perca flavescens, became microscopically detectable several weeks after the invasion. In 2011, we detected $K$. yasunagai DNA from the brain $10 \mathrm{~d}$ after fish were placed in the net cage. This indicates that $K$. yasunagai may take less than $10 \mathrm{~d}$ to reach the brain after invasion into the fish.

In both 2010 and 2011, Kudoa yasunagai cysts (plasmodia) appeared on the brain surface 4 wk after the parasite was detected by the PCR. During the subsequent $4 \mathrm{wk}$, the average number of cysts showed a $400 \%$ increase. In the laboratory experiment, no cysts were found in fish at the beginning (95\% positive by PCR), but the encysting prevalence reached over $50 \%$ within the following $4 \mathrm{wk}$. These results suggest that the development of cysts in the brain takes at least $4 \mathrm{wk}$ and over $8 \mathrm{wk}$ in some cases. This duration is comparable with other myxozoans. The duration of plasmodium development and spore formation may range from less than $3 \mathrm{wk}\left(\right.$ at $\left.17.8^{\circ} \mathrm{C}\right)$ in Ceratomyxa shasta (Yamamoto \& Sanders 1979) to nearly 6 mo (average temperature $14^{\circ} \mathrm{C}$ ) in $K$. thyrsites (Moran et al. 1999a,b,c). Combining the results of our monitoring and laboratory experiments, the infection dynamics of $K$. yasunagai in juvenile Seriola quinqueradiata is considered as follows. Actinospores are released from invertebrate hosts and start to invade fish in late June or early July. The parasites reach the brain within a few weeks by mid-July, gradually multiply, and develop into the spores in a few months. By mid-August, they start to form plasmodia and the cysts become visible on the brain surface. It remains unclear whether the infection occurs primarily in mid-July or continues for the rest of the year. 
Our study also raised a question about the fate of the parasite. Throughout the experiment, we consistently found a considerable proportion of infected fish without cysts. This seems unusual. Since the majority of experimental fish had become infected in July and August, the proportion of fish with cysts should keep increasing as the parasites develop. However, the encysting prevalence never reached $100 \%$, except for one sampling in August 2010. Moreover, after reaching the initial peak of 90 to $100 \%$, the infection prevalence (PCR and cysts) became variable between the samplings and never reached a plateau. There were only a few mortalities and no new fish were added to the cage. Therefore, the possible explanations for such phenomena include (1) artifacts of experimental procedures, such as non-random sampling caused overestimation of prevalence and/or inaccuracy in parasite detection, (2) the parasite never developed into cysts in some fish, or (3) the parasite developed into cysts but disappeared after a while.

The probability of the first scenario is quite low because we randomly sampled the fish and a single person performed the PCR (with both negative and positive controls) and microscopic observation in which probability of overlooking relatively large Kudoa yasunagai cysts (>1 mm in some cases) is low. The second explanation is possible. Although we used hatchery-reared fish with low genetic diversity (S. Shirakashi unpubl. data), individual variation may lead to differences in the development rate of the cysts. However, even if cyst formation was delayed in some fish, the infection should accumulate in the population and the proportion of infected fish without cysts should eventually reach a high plateau. We suggest the third explanation is the most likely. After the formation of the cysts, or even before cyst formation in some cases, some parasites might have disappeared from the brain, possibly by the host immune response. This hypothesis is also supported by the declining tendency of cyst intensity, which otherwise should increase over time. Degeneration or rupture of cysts has been observed in several myxozoan-fish systems. Myxobolus artus cysts in the skeletal muscle of common carp Cyprinus carpio degenerate and spores are transferred to gill lamellae causing anemia (Ogawa et al. 1992, Yokoyama et al. 1996). Similarly, degeneration of Henneguya lateolabracis plasmodia in the bulbus arteriosus of Chinese sea bass Lateolabrax sp. causes gill damage by the massive influx of spores. Degeneration of plasmodia has been observed in Kudoa ciliatae (Hallett et al. 1997) and K. thyrsites (Moran et al. 1999b) as well. However, whether degeneration and elimination of parasite cysts occurs in the brain of yellowtail is not clear. We did not observe obvious residual or degenerating cysts. Histological studies are currently being undertaken, and hopefully this will reveal the underlying mechanisms behind the observed phenomena. We hypothesized that the sudden sharp decline of prevalence observed in August 2010 is due to elimination of the parasite under high water temperature conditions. If this is the case, it opens up the possibilities of developing a control measure. However, our hypothesis was not supported by the laboratory experiment. There was no difference in the infection prevalence, encysting prevalence and cyst intensity between the fish kept at 25 and $30^{\circ} \mathrm{C}$, suggesting similar parasite development at both temperatures. This indicates that the water temperatures in our tested range affect neither development nor survival of $K$. yasunagai. Although the overall prevalence in the $30^{\circ} \mathrm{C}$ group appeared to decline at the end of the experiment, this difference was not statistically significant. Long-term experiments may provide different results. However, in the monitoring experiment, infection prevalence showed a $60 \%$ decline within $4 \mathrm{wk}$, and such a drastic change was not observed in the laboratory. Therefore, the decline of prevalence observed in the monitoring experiment is likely to have been caused by factors other than temperature, or a combination of various factors. The upper threshold for the $K$. yasunagai could possibly be $30^{\circ} \mathrm{C}$, with infection diminishing at higher temperatures. Fish immunity may also be important because low temperatures have an adverse effect on immune response (Le Morvan et al. 1998). High density and stressful laboratory conditions might suppress the fish immune response which otherwise would reduce infection as in the net cage condition. The reduced infection in high temperature season could simply be an artifact of sampling, and we need to continue monitoring to see if a similar phenomenon consistently occurs.

Unexpectedly we did not see obvious pathologies in our experimental fish despite high Kudoa yasunagai infection. Mortality was minimal; only 6 fish died in $15 \mathrm{mo}(<1 \%)$. We observed occasional erratic swimming, but they were likely associated with the skin fluke infections. Several fish possessed abnormal spinal curvature (head bent upward), but their infection prevalence was only $33 \%$, lower than overall average. A V-shaped spinal curvature, similar to the one observed in the present study, is known to be caused by abnormal development of the swim bladder (Kitajima et al. 1994). Considering the low infection prevalence and the type of spinal curvature, we believe that the spinal deformities seen in the ex- 
perimental fish were not associated with Kudoa yasunagai, but probably the abnormality of hatcheryreared fish. It remains unknown why there were no apparent clinical signs in the infected yellowtail while kingfish, a member of the same genus, showed severe whirling and scoliosis. Differences in pathological effects between fish species have been documented in other brain-infecting myxozoans. For instance, Myxobolus acanthogobii causes severe dorsoventral spinal curvature (kyphosis) in cultured chub mackerel, S-curvature (scoliosis) in yellowtail, and irregular deformities in Japanese bluefish Scombrops boops, but appears to cause no skeletal abnormalities in yellowfin goby Acanthogobius flavimanus and brown-lined puffer Canthigaster rivulata (Yokoyama et al. 2004, 2005). K. yasunagai may have less effect on yellowtail than kingfish. However, there have been records of spinal curvature in $K$. yasunagaiinfected yellowtail (H. Yokoyama pers. comm.). The combination of various factors such as host growth rate, age of fish at infection, parasite development speed, infection site within the brain, and/or environmental factors may be important in the development of pathological signs.

Our study raised more questions than it provided answers. Our knowledge about general biology, lifecycle, infection dynamics and host-parasite interaction of Kudoa spp. is still very limited. We believe accumulation of basic information is important to deepen our understanding of Kudoa and develop control measures in aquaculture.

Acknowledgements. The authors thank the members of the Fish Pathology Laboratory at Kinki University for their support in fish keeping, sample collection and processing. Thanks are also due to D. Grabner of University of Duisburg-Essen for his comments on the earlier version of the manuscript. This study was supported by Global COE program of Kinki University.

\section{LITERATURE CITED}

Burger MAA, Adlard RD (2010) Phenotypic variation in a significant spore character in Kudoa (Myxosporea: Multivalvulida) species infecting brain tissue. Parasitology 137:1759-1772

> Cheung PJ, Nigrelli RF (1990) Coccomyxa (Myxosporea: Bivalvulida) and Septemcapsula (Myxosporea: Multivalvulida) infections, the possible cause of death of coral catfish Plotosus anguillaris in captivity. J Aquat Anim Health 2:112-118

> Dzulinksy K, Cone DK, Faulkner GT, Cusack R (1994) Development of Myxobolus neurophilus (Guilford, 1963) (Myxosporea) in the brain of yellow perch (Perca flavescens) in Vinegar Lake, Nova Scotia. Can J Zool 72: $1180-1185$
Egusa S (1986a) A myxosporean of the order Multivalvulida from the brains of Lateolabrax japonicus and some other marine fishes. Fish Pathol 21:233-238

Egusa S (1986b) The order Multivalvulida Schulman, 1959 (Myxozoa, Myxosporea): a review. Fish Pathol 21: 261-274 (in Japanese)

> Hallett SL, O'Donoghue PJ, Lester RJG (1997) Infections by Kudoa ciliatae (Myxozoa: Myxosporea) in Indo-Pacific whiting Sillago spp. Dis Aquat Org 30:11-16

> Holzer AS, Schachner O (2001) Myxosporidia and macrophage centres in chub (Leuciscus cephalus)-quantitative interactions focus on Myxobolus cyprini. Parasitology 122:55-62

Holzer AS, Sommerville C, Wootten R (2006) Molecular studies on the seasonal occurrence and development of five myxozoans in farmed Salmo trutta L. Parasitology 132:193-205

Hsieh S, Chen C (1984) Septemcapsula yasunagai gen. et sp. nov., representative of a new family of the class Myxosporea. Acta Zootaxon Sin 9:225-227

Kent ML, Margolis L, Whitaker DJ, Hoskins GE, McDonald TE (1994) Review of Myxosporea of importance in salmonid fisheries and aquaculture in British Columbia. Folia Parasitol 41:27-37

Kent ML, Andree KB, Bartholomew JL, El-Matbouli M and others (2001) Recent advances in our knowledge of the Myxozoa. J Eukaryot Microbiol 48:395-413

> Kitajima C, Watanabe T, Tsukashima Y, Fujita S (1994) Lordotic deformation and abnormal development of swim bladders in some hatchery-bred marine physoclistous fish in Japan. J World Aquacult Soc 25:64-77

> Le Morvan C, Troutaud D, Deschaux P (1998) Differential effects of temperature on specific and nonspecific immune defences in fish. J Exp Biol 201:165-168

> Markiw ME (1991) Whirling disease: earliest susceptible age of rainbow trout to the triactinomyxid of Myxobolus cerebralis. Aquaculture 92:1-6

> Markiw ME (1992) Experimentally induced whirling disease. I. Dose response of fry and adults of rainbow trout exposed to the triactinomyxon stage of Myxobolus cerebralis. J Aquat Anim Health 4:40-43

Meng F, Yokoyama H, Shirakashi S, Grabner D and others (2011) Kudoa prunusi n. sp. (Myxozoa: Multivalvulida) from the brain of Pacific bluefin tuna Thunnus orientalis (Temminck \& Schlegel, 1844) cultured in Japan. Parasitol Int 60:90-96

> Moran JDW, Kent ML, Whitaker DJ (1999a) Kudoa thyrsites (Myxozoa: Myxosporea) infections in pen-reared Atlantic salmon in the northeast Pacific Ocean with a survey of potential nonsalmonid reservoir hosts. J Aquat Anim Health 11:101-109

Moran JDW, Margolis L, Webster JM, Kent ML (1999b) Development of Kudoa thyrsites (Myxozoa: Myxosporea) in netpen-reared Atlantic salmon determined by light microscopy and a polymerase chain reaction test. Dis Aquat Org 37:185-193

Moran JDW, Whitaker DJ, Kent ML (1999c) Natural and laboratory transmission of the marine myxozoan parasite Kudoa thyrsites to Atlantic salmon. J Aquat Anim Health 11:110-115

> Moran JDW, Whitaker DJ, Kent ML (1999d) A review of the myxosporean genus Kudoa Meglitsch, 1947, and its impact on the international aquaculture industry and commercial fisheries. Aquaculture 172:163-196

Ogawa K, Delgahapitiya KP, Furuta T, Wakabayashi H 
(1992) Histological studies on the host response to Myxobolus artus Akhmerov, 1960 (Myxozoa, Myxobolidae) infection in the skeletal muscle of carp, Cyprinus carpio L. J Fish Biol 41:363-371

Whipps CM, Grossel G, Adlard RD, Yokoyama H, Bryant MS, Munday BL, Kent ML (2004) Phylogeny of the Multivalvulidae (Myxozoa: Myxosporea) based on comparative ribosomal DNA sequence analysis. J Parasitol 90: $618-622$

Yamamoto S (2007) Chub mackerel. In: Kumai H, Mori K, Takashima T (eds) Aquaculture system 4: atlas. Kouseisya Kouseikaku, Tokyo, p 291-310 (in Japanese)

Yamamoto T, Sanders JE (1979) Light and electron microscopic observations of sporogenesis in the Myxosporida, Ceratomyxa shasta (Noble, 1950). J Fish Dis $2: 411-428$

Yasunaga N, Hatai K, Ogawa K, Yasumoto S (1981) An unknown Myxozoa found in brain of cultured sea bass, Lateolabrax japonicus and cultured Japanese striped knifejaw, Oplegnathus fasciatus. Fish Pathol 16:51-54 (in Japanese)

Editorial responsibility: David Marcogliese, Montreal, Quebec, Canada
Yokoyama H, Danjo T, Ogawa K, Arima T, Wakabayashi H (1996) Hemorrhagic anemia of carp associated with spore discharge of Myxobolus artus (Myxozoa: Myxosporea). Fish Pathol 31:19-23 (in Japanese)

Yokoyama H, Freeman MA, Yoshinaga T, Ogawa K (2004) Myxobolus buri, the myxosporean parasite causing scoliosis of yellowtail, is synonymous with Myxobolus acanthogobii infecting the brain of the yellowfin goby. Fish Sci 70:1036-1042

Yokoyama H, Freeman MA, Itoh N, Fukuda Y (2005) Spinal curvature of cultured Japanese mackerel Scomber japonicus associated with a brain myxosporean, Myxobolus acanthogobii. Dis Aquat Org 66:1-7

Yokoyama H, Grabner D, Shirakashi S (2012) Transmission biology of the Myxozoa. In: Carvalho ED, David GS, Silva RJ (eds) Health and environment in aquaculture. InTech, Rijeka, p 3-42

> Zhang J, Meng F, Yokoyama H, Miyahara J, Takami I, Ogawa K (2010) Myxosporean and microsporidian infections in cultured Pacific bluefin tuna Thunnus orientalis in Japan. Fish Sci 76:981-990

Submitted: May 21, 2012; Accepted: August 1, 2012 Proofs received from author(s): October 16, 2012 